NASA/TM-1999-208835

(2)

Rare Earth Doped Yttrium Aluminum Garnet (YAG) Selective Emitters

Donald L. Chubb

Glenn Research Center, Cleveland, Ohio

AnnaMarie T. Pal, Martin O. Patton, and Phillip P. Jenkins

Essential Research, Inc., Cleveland, Ohio

Prepared for the

Fall Meeting

sponsored by The Materials Research Society

Boston, Massachusetts, November 29-December 4, 1998

National Aeronautics and

Space Administration

Glenn Research Center

May 1999 
Available from

NASA Center for Aerospace Information 7121 Standard Drive Hanover, MD 21076

Price Code: A03
National Technical Information Service 5285 Port Royal Road Springfield, VA 22100 Price Code: A03 


\title{
RARE EARTH DOPED YTTRIUM ALUMINUM GARNET (YAG) SELECTIVE EMITTERS
}

\author{
Donald L. Chubb* \\ National Aeronautics and Space Administration \\ Glenn Research Center \\ Cleveland, Ohio 441.35 \\ AnnaMaria T. Pal, Martin O. Patton, and Phillip P. Jenkins \\ Essential Research. Inc. \\ Cleveland, Ohio 44122
}

\begin{abstract}
SUMMARY
As a result of their electron structure, rare earth ions in crystals at high temperature emit radiation in several narrow bands rather than in a continuous blackbody manner. This study presents a spectral emittance model for films and cylinders of rare earth doped yttrium aluminum garnets. Good agreement between experimental and theoretical film spectral emittances was found for erbium and holmium aluminum garnets. Spectral emittances of films are sensitive to temperature differences across the film. For operating conditions of interest, the film emitter experiences a linear temperature variation whereas the cylinder emitter has a more advantageous uniform temperature. Emitter efficiency is also a sensitive function of temperature. For holminum aluminum garnet film the efficiency is 0.35 at $1446 \mathrm{~K}$ but only 0.27 at $1270 \mathrm{~K}$.
\end{abstract}

\section{INTRODUCTION}

A selective emitter is a material that emits optical radiation in a few emission bands rather than in a continuous spectrum like a blackbody or a gray body (constant emittance). Thermophotovoltaic (TPV) energy conversion is the main application for selective emitters. In TPV energy conversion, the selective emitter converts thermal energy to near infrared radiation at wavelengths where photovoltaic energy conversion is efficient. A TPV system is rather simple, consisting of three main components, a heat source, an emitter and a photovoltaic cell array.

The ideal selective emitter would have a single emission band with an emittance approaching one within the band and negligible emittance outside the emission band. For the photon energy or wavelength region of interest for TPV energy conversion ( 1000 to $3000 \mathrm{~nm}$ ), an electronic transition of an atom or molecule is required to produce the desired radiation. However, when atoms are compressed to solid state densities the emission is not characterized by narrow band emission as with an isolated atom, but by a continuous emission spectrum.

Fortunately, there is a group of atoms that even at solid state densities behave nearly like isolated atoms. These are the lanthanides or rare earth atoms. For doubly and triply charged ions of these elements in crystals the orbits of the valence $4 \mathrm{f}$ electrons, which account for emission and absorption, lie inside the $5 \mathrm{~s}$ and $5 \mathrm{p}$ electron orbits. The $5 \mathrm{~s}$ and $5 p$ electrons "shield" the $4 \mathrm{f}$ valence electrons from the surrounding ions in the crystal. As a result, the rare earth ions in the solid state emit in narrow bands rather than in a continuous gray body manner. For the temperatures of interest $(1200 \leq \mathrm{T} \leq 2000 \mathrm{~K})$ the rare earths of most interest have a strong emission band in the near infrared $(800 \leq \lambda \leq 3000 \mathrm{~nm})$ resulting from electron transitions from the first excited state manifold to the ground state manifold. The rare earths of most interest for selective emitters are ytterbium (Yb), thulium (Tm), erbium (Er), holmium (Ho) and dysprosium (Dy). The spectra of the rare earth ions in crystals have been extensively studied. Most of this work is summarized in the text of Dieke (ref. 1).

The first selective emitters investigated (ref. 2) were made by sintering rare earth oxide powders. These emitters showed the strong emission bands. However, emittance outside the emission bands was also large so that the emitter efficiency was low. In the late 1980's Nelson and Parent (refs. 3 and 4) reported a large improvement in rare earth oxide emitters. Their emitters are constructed of bundles of small diameter $(51010 \mu \mathrm{m})$ fibers similar to the construction of the Welsbach mantle used in gas lanterns. The very small characteristic dimension of these emitters

${ }^{*}$ Corresponding author. 
results in low emittance outside the emission band and thus greatly increased efficiency. The fibrous selective emitters are well suited to a combustion driven TPV system where the fibrous mantle surrounds the flame. However, for coupling to other thermal energy sources likely to be used for a space TPV system, such as nuclear or solar, the fibrous emitter is not so well suited. As just stated, it was the small characteristic dimension that made the fibrous emitters efficient. Another geometry for achieving a small characteristic dimension and also easily coupling to any thermal source is a film. A film containing a rare earth on a low emittance substrate, which blocks radiation from the thermal source, can be easily attached to any thermal source. In addition, a film is more durable than a fibrous geometry. Therefore, we began a theoretical and experimental investigation of rare earth containing film selective emitters (refs. 5 to 13).

Our first attempt at producing a film selective emitter was by electron beam evaporation of pure rare earth oxides. However, we soon learned that film thicknesses on the order 1 to $10 \mu \mathrm{m}$ were not sufficient to produce large emittance. Film thicknesses of 0.1 to $1 \mathrm{~mm}(100$ to $1000 \mu \mathrm{m})$ are required. Evaporation is not applicable for films of that thickness so we looked for other methods. We knew that yttrium aluminum garnet (YAG) could be doped with rare earths and grown in single crystal form. Therefore, with material in this form we could cut and polish a sample to any thickness. Thus our first successful selective emitters were single crystal rare earth doped YAG. Although there are many other possible high temperature host materials for rare earths, this study is confined to rare earth doped YAG emitters.

The optical properties that characterize a selective emitter are the extinction coefficient, $\alpha_{\lambda}$, which is the sum of the absorption coefficient, $a_{\lambda}$, and the scattering coefficient, $\sigma_{\lambda}$, and the index of refraction, $n$. Knowing $\alpha_{\lambda}$ and $n$, the spectral emittance, $\varepsilon_{\lambda}$, can be calculated. In the next section the theoretical spectral emittance model for both a film and a cylinder will be presented. Figure 1 shows the extinction coefficient for single crystal erbium aluminum garnet $\left(\mathrm{Er}_{3} \mathrm{Al}_{5} \mathrm{O}_{12}\right)$. Although the results in figure 1 apply for erbium aluminum garnet, qualitatively similar results will occur for any of the possible erbium containing materials. The major emission band for Er occurs at wavelength, $\lambda \approx 1500 \mathrm{~nm}$, with smaller bands occurring at $\lambda \approx 970 \mathrm{~nm}, 800 \mathrm{~nm}$ and $640 \mathrm{~nm}$. Most all high temperature ceramic materials have large extinction coefficient and thus large absorptance and emittance at long wavelengths. For YAG and the rare earth aluminum garnets this region begins at $\lambda \approx 5000 \mathrm{~nm}$. Obviously this long wavelength region of high emittance is undesirable for a selective emitter. An efficient selective emitter is one that emits most of its energy in the large emission band.

The next section presents the spectral emittance model for both an emitting film and a cylinder, which is an approximation to the fibrous emitter. After that the effect on $\varepsilon_{\lambda}$ of the temperature drop between the front and back surfaces of an emitting film and rare earth doping level are presented. Finally, we present spectral emittance and emitter efficiency results for a film emitter of erbrium aluminum garnet $\left(\mathrm{Er}_{3} \mathrm{Al}_{5} \mathrm{O}_{12}\right)$ and for both a film and cylindrical holmium aluminum garnet $\left(\mathrm{Ho}_{3} \mathrm{Al}_{5} \mathrm{O}_{12}\right)$ emitter.

\section{Theoretical Spectral Emittance}

Spectral emittance is usually thought of as a surface property. However, emitted photons originate at various distances below the surface. For metals these distances are very small $(<1 \mu \mathrm{m})$. But in the case of a dielectric, such as rare earth doped YAG, these distances are greater than $100 \mu \mathrm{m}$. Since rare earth doped YAG also has low thermal conductivity $(0.01 \mathrm{~W} / \mathrm{cm} \mathrm{K})$ this means that significant temperature changes can occur even for small distances. As a result, since thermal radiation is a sensitive function of temperature the spectral emittance is also sensitive to the temperature changes.

Temperature changes depend on geometry, as well as, thermal conductivity and radiation transfer. For steady state conditions the conservation of energy is given by the following equation.

$$
\nabla\left[\mathrm{k}_{\mathrm{th}} \nabla \mathrm{T}-\mathrm{Q}\right]=0
$$

Where $k_{t h}$ is the thermal conductivity, $T$ is the temperature and $Q$ is the total radiation flux.

$$
Q=\int_{0}^{\infty} q_{\lambda} d \lambda \quad W / \mathrm{cm}^{2}
$$

and $q_{\lambda}$ is the radiation flux at wavelength, $\lambda$, and has the units $W / \mathrm{cm}^{2} \mathrm{~nm}$. 
Now consider equation (1) for a film emitter as shown in figure 2(a). In this case the film thickness is small compared to the dimensions perpendicular to the film. As a result, we assume the temperature and radiation depend only on the $\mathrm{x}$-coordinate. Therefore, equation (1) becomes the following.

$$
-\mathrm{k}_{\mathrm{th}} \frac{\mathrm{dT}}{\mathrm{dx}}+\mathrm{Q}(\mathrm{x})=\mathrm{Q}_{\mathrm{in}}=\mathrm{constant}
$$

Where $Q_{\text {in }}$ is the thermal energy entering through the substrate. The radiation flux will always be less than the blackbody flux $\sigma_{s b} T_{s}^{4}$, where $\sigma_{s b}$ is the Stefan-Boltzmann constant $\left(5.67 \times 10^{-12} \mathrm{~W} / \mathrm{cm}^{2} \mathrm{~K}^{4}\right)$ and $\mathrm{T}_{\mathrm{s}}$ is the substrate temperature. Therefore, defining the following dimensionless variables.

$$
\overline{\mathrm{T}}=\frac{\mathrm{T}}{\mathrm{T}_{\mathrm{s}}}, \quad \overline{\mathrm{Q}}=\frac{\mathrm{Q}}{\sigma_{\mathrm{sb}} \mathrm{T}_{\mathrm{s}}^{4}}, \quad \overline{\mathrm{x}}=\frac{\mathrm{x}}{\mathrm{d}}
$$

Results in the following energy equation.

$$
-\frac{\mathrm{d} \overline{\mathrm{T}}}{\mathrm{d} \overline{\mathrm{x}}}+\gamma \overline{\mathrm{Q}}=\gamma \overline{\mathrm{Q}}_{\mathrm{in}}=\mathrm{constant}
$$

Where $\gamma$ is the ratio of the radiation flux to the thermal conduction flux.

$$
\gamma \equiv \frac{\sigma_{\mathrm{sb}} \mathrm{T}_{\mathrm{s}}^{4}}{\mathrm{k}_{\mathrm{th}} \frac{\mathrm{T}_{\mathrm{s}}}{\mathrm{d}}}=\frac{\sigma_{\mathrm{sb}} \mathrm{T}_{\mathrm{s}}^{3} \mathrm{~d}}{\mathrm{k}_{\mathrm{th}}}
$$

Thus, if $\gamma<1$ the radiation term can be neglected and the solution to equation (4) is the following.

$$
\overline{\mathrm{T}}=1-\overline{\mathrm{x}} \Delta \mathrm{T}
$$

Where,

$$
\Delta T=\frac{T_{s}-T_{f}}{T_{s}}
$$

For most of the materials considered for rare earth selective emitters $k_{t h} \geq 0.01 \mathrm{~W} / \mathrm{cmK} . \mathrm{T}_{\mathrm{s}} \leq 2000 \mathrm{~K}$ and $\mathrm{d} \leq 0.05 \mathrm{~cm}$. Thus, $\gamma$ will be less than 0.2 . The linear temperature gradient given by equation $(8)$ will be used in calculating the spectral emittance of a film emitter.

Now consider the energy equation for a cylindrical emitter as shown in figure $2(\mathrm{~b})$. Assuming that $\mathrm{T}$ and $\mathrm{Q}$ depend only on the radial coordinate, $r$, equation (1) becomes the following.

$$
r\left[k_{\text {th }} \frac{d T}{d r}-Q\right]=\text { constant }
$$

In order to avoid the term in brackets being singular at $r=0$ it must vanish for all $r$. Thus at all $r$ the conduction and radiation fluxes balance.

$$
\mathrm{k}_{\mathrm{th}} \frac{\mathrm{dT}}{\mathrm{dr}}=\mathrm{Q}
$$

In other words, for steady state conditions all the thermal energy being conducted into the cylinder at the outer radius, $r=R$, leaves the cylinder as radiation. Define the following dimensionless quantities. 


$$
\bar{Q}=\frac{Q}{\sigma_{s b} T_{s}^{4}} \quad \bar{T}=\frac{T}{T_{s}} \quad \overline{\mathbf{r}}=\frac{r}{R}
$$

Where again, $T_{s}$ is the temperature at $r=R$. In this case equation ( 10 ) becomes the following.

$$
\frac{\mathrm{d} \overline{\mathbf{T}}}{\mathrm{d} \overline{\mathrm{r}}}=\gamma \overline{\mathrm{Q}}
$$

Where again, $\gamma$ is the ratio of the radiation flux to the thermal conduction flux.

$$
\gamma \equiv \frac{\sigma_{\mathrm{sb}} \mathrm{T}_{\mathrm{s}}^{4}}{\mathrm{k}_{\mathrm{th}} \frac{\mathrm{T}_{\mathrm{s}}}{\mathrm{R}}}=\frac{\sigma_{\mathrm{sb}} \mathrm{T}_{\mathrm{s}}^{3} \mathrm{R}}{\mathrm{k}_{\mathrm{th}}}
$$

Therefore, for $\mathrm{k}_{\mathrm{th}} \geq 0.01 \mathrm{~W} / \mathrm{cmK}, \mathrm{T}_{\mathrm{s}} \leq 2000 \mathrm{~K}$ and $\mathrm{R}<0.1 \mathrm{~cm}$ it is a reasonable approximation to neglect the right hand side of equation (12) and obtain the result $\overline{\mathrm{T}}=$ constant $\left(\mathrm{T}=\mathrm{T}_{\mathrm{s}}\right.$ ).

Thus depending on the geometry, there are two different results for temperature in the case of small $\gamma$. For a planar film geometry the temperature is a linear function of $x$. But in the case of a cylinder the temperature is a constant for $\gamma \ll 1$. In calculating the spectral emittance for a cylinder the temperature was assumed constant.

To determine the spectral emittance, $\varepsilon_{\lambda}$, of a film emitter the radiation flux leaving the film at $x=d, q_{\lambda}(d)$, must be calculated since $\varepsilon_{\lambda}$ is defined as follows.

$$
\varepsilon_{\lambda} \equiv \frac{q_{\lambda}(d)}{e_{b s}\left(\lambda, T_{s}\right)}=\frac{q_{\lambda}(d)}{\pi i_{b s}\left(\lambda, T_{s}\right)}
$$

Similarly, for a cylinder the spectral emittance is the following.

$$
\varepsilon_{\lambda} \equiv \frac{q_{\lambda}(R)}{e_{b s}\left(\lambda, T_{s}\right)}=\frac{q_{\lambda}(R)}{\pi i_{b s}\left(\lambda, T_{s}\right)}
$$

Where $e_{b s}\left(\lambda, T_{s}\right)$ is the blackbody emissive power and $T_{s}$ is the substrate temperature for the film or the cylinder temperature.

$$
\mathrm{e}_{\mathrm{bs}}\left(\lambda, \mathrm{T}_{\mathrm{s}}\right)=\pi \mathrm{i}_{\mathrm{bs}}\left(\lambda, \mathrm{T}_{\mathrm{s}}\right)=\frac{2 \pi h c_{\mathrm{o}}^{2}}{\lambda^{5}\left[\exp \left(h \mathrm{c}_{\mathrm{o}} / \lambda \mathrm{kT} \mathrm{T}_{\mathrm{s}}\right)-1\right]}
$$

The radiation flux, $\mathrm{q}_{\lambda}$. is obtained by solving the radiation transfer equation with the appropriate boundary conditions. These boundary conditions depend on the reflectances at the film-vacuum, $\rho_{f 0}$, and film-substrate, $\rho_{\mathrm{fs}}$, interfaces and the emittance at film-substrate interface, $\varepsilon_{\mathrm{fs}}=1-\rho_{\mathrm{fs}}$. In solving the radiation transfer equation the intensity, $i_{\lambda}$, is split into positive going $(+x$ or $+r$ direction) and negative going $(-x$ or $-r$ direction) components (ref. 14). In this case the flux $\varphi_{\lambda}$ is given as follows.

$$
\mathrm{q}_{\lambda}=\mathrm{q}_{\lambda}^{+}-\mathrm{q}_{\lambda}^{-}=2 \pi \int_{0}^{\pi / 2} \mathrm{i}^{+} \cos \theta \sin \theta \mathrm{d} \theta-2 \pi \int_{\pi / 2}^{\pi} \mathrm{i}_{\lambda}^{-} \cos \theta \sin \theta \mathrm{d} \theta
$$

The emittance theory neglecting scattering for the film emitter is presented in reference 15 and for the cylinder in reference 16. Since the rare earth doped YAG emitters are single crystal, scattering will be small compared to absorption and emission. For a film emitter with a linear temperature gradient the spectral emittance is the following 


$$
\varepsilon_{\lambda} \equiv \frac{\mathrm{q}_{\lambda}\left(\mathrm{K}_{\mathrm{d}}\right)}{\mathrm{e}_{\mathrm{bs}}\left(\lambda, \mathrm{T}_{\mathrm{s}}\right)}=\frac{2 \mathrm{n}_{\mathrm{f}}^{2}\left(1-\rho_{\mathrm{fo}}\right)}{\mathrm{DEN}}\left\{\left[\frac{\varepsilon_{\mathrm{fs}}}{\mathrm{n}_{\mathrm{f}}^{2}}+2 \rho_{\mathrm{fs}} \bar{\Phi}_{-}\left(\mathrm{K}_{\mathrm{d}}\right)\right] \mathrm{h}_{-}+\bar{\Phi}_{+}\left(\mathrm{K}_{\mathrm{d}}\right) \mathrm{h}_{+}-\bar{\Phi}_{\mathrm{M}}\left(\frac{\mathrm{K}_{\mathrm{d}}}{\mu_{\mathrm{M}}}\right) \mathrm{h}_{\mathrm{M}}\right\}
$$

Where,

$$
\begin{gathered}
\operatorname{DEN}=1-\rho_{\mathrm{fs}} E_{3}\left(K_{d}\right)\left[\rho_{f o} E_{3}\left(K_{d}\right)+\left(1-\rho_{f o}\right) \mu_{M}^{2} E_{3}\left(\frac{K_{d}}{\mu_{m}}\right)\right] \\
h_{-}=E_{3}\left(K_{d}\right)-\mu_{M}^{2} E_{3}\left(\frac{K_{d}}{\mu_{M}}\right) \\
h_{+}=1-4 \rho_{f s} \mu_{M}^{2} E_{3}\left(K_{d}\right) E_{3}\left(\frac{K_{d}}{\mu_{M}}\right) \\
\Phi_{+}\left(K_{d}\right)=K_{d}\left(e^{u}-1\right) \int_{0}^{1} \frac{E_{2}\left[K_{d}(1-v)\right]}{\exp \left[\frac{u}{1-v \Delta T}\right]-1} d v \\
\bar{\Phi}_{M}\left(\frac{K_{d}}{\mu_{M}}\right)=\mu_{M} K_{d}\left(e^{u}-1\right) \int_{0}^{1} \frac{E_{2}\left[\frac{K_{d}}{\mu_{M}}(1-v)\right]}{\exp \left[\frac{u}{1-v \Delta T}\right]-1} d v \\
\bar{\Phi}_{-}\left(K_{d}\right)=K_{d}\left(e^{u}-1\right) \int_{0}^{1} \frac{E_{2}^{2}\left(K_{d}\right)}{\exp \left[\frac{u}{1-v \Delta T}\right]-1} d v
\end{gathered}
$$

Where $\Delta \mathrm{T}$ is the temperature gradient given by equation (8) and

$$
\begin{gathered}
u=\frac{h c_{o}}{\lambda k T_{s}} \\
v=\frac{K}{K_{d}}=\frac{x}{d} \\
E_{n}(x)=\int_{0}^{1} z^{n-2} \exp \left(-\frac{x}{z}\right) d z
\end{gathered}
$$




$$
\mu_{M}^{2}=1-\left(\frac{n_{0}}{n_{f}}\right)^{2}
$$

As equation (18) shows, an important variable for determining $\varepsilon_{\lambda}$ is the optical depth, $K_{d}$, which is the product of the extinction coefficient, $\alpha_{\lambda}$, and the thickness, $d$.

$$
K_{d}=\alpha_{\lambda} d
$$

Another important parameter for determining $\varepsilon_{\lambda}$ for a film emitter is the temperature change $\Delta T$. This will be discussed later.

From equation (18) we see that the emittance is made up of three parts. The coefficient of the $h$ term represents the radiation leaving the substrate plus the radiation reflected back into the film from the film-substrate interface. This part of the emittance decreases with increasing optical depth, $\mathrm{K}_{\mathrm{d}}$. The second part of the emittance, $\bar{\Phi}_{+} \mathrm{h}_{+}$, represents the radiation emitted within the film and increases with increasing $K_{d}$. The last part of $\varepsilon_{\lambda}$ is the negative term, $-\bar{\Phi}_{M} h_{M}$, which represents the radiation with angle of incidence $\theta>\theta_{M}$ that is totally reflected back into the film at the film-vacuum interface. This part increases with increasing optical depth.

Spectral emittance results for a cylinder of radius, $R$, at uniform temperature, $T_{s}$, can be obtained by setting $\varepsilon_{\mathrm{fs}}=0\left(\rho_{\mathrm{fs}}=1\right)$ and $\Delta \mathrm{T}=0$ in equations (19) to (25) (ref. 15). When this is done the following result is obtained.

$$
\varepsilon_{\lambda}=\frac{n_{\mathrm{o}}^{2}\left(1-\rho_{\mathrm{fo}}\right)\left[1-4 \mathrm{E}_{3}^{2}\left(\mathrm{~K}_{\mathrm{R}}\right)\right]}{1-4 \mathrm{E}_{3}\left(\mathrm{~K}_{\mathrm{R}}\right)\left[\rho_{\mathrm{fo}} \mathrm{E}_{3}\left(\mathrm{~K}_{\mathrm{R}}\right)+\mu_{M}^{2}\left(1-\rho_{\mathrm{fo}}\right) \mathrm{E}_{3}\left(\frac{\mathrm{K}_{\mathrm{R}}}{\mu_{\mathrm{M}}}\right)\right]}
$$

cylinder at uniform temperature and no scattering

In this case the optical depth is the following.

$$
K_{R}=\alpha_{\lambda} R
$$

\section{Effect of Temperature Gradient on Spectral Emittance of Emitting Film}

To calculate $\varepsilon_{\lambda}$ the extinction coefficient, $\alpha_{\lambda}$, and index of refraction, $n_{f}$, must be known. These quantities were obtained from measured transmittance and reflectance data (ref. 15). Also, the reflectances at the film-vacuum interface, $\rho_{\mathrm{fo}}$ and film-substrate interface, $\rho_{\mathrm{fs}},\left(\varepsilon_{\mathrm{fs}}=1-\rho_{\mathrm{fs}}\right)$ must be known. For $\rho_{\mathrm{fo}}$ the value for normal reflectance was used.

$$
\rho_{f o}=\left(\frac{n_{f}-n_{o}}{n_{f}+n_{o}}\right)^{2}
$$

For $\rho_{\mathrm{fs}}$ the value for normal reflectance for a metal into a dielectric (ref. 14) was used.

$$
\rho_{\mathrm{fs}}=\left(1-\varepsilon_{\mathrm{fs}}\right)=\frac{\left(n_{\mathrm{s}}-n_{\mathrm{f}}\right)^{2}+n_{\mathrm{sl}}^{2}}{\left(n_{\mathrm{s}}+n_{\mathrm{f}}\right)^{2}+n_{\mathrm{sl}}^{2}}
$$

Included in equation (34) are the real, $\mathrm{n}_{\mathrm{s}}$, and imaginary parts, $\mathrm{n}_{\mathrm{s}}$, of the substrate index of refraction.

Since radiation is strongly dependent on temperature there will be a significant effect of temperature gradient. $\Delta \mathrm{T}$, on the spectral emittance of an emitting film. This can be shown by using the spectral emittance model of the previous section. Using the extinction coefficient data for erbium aluminum garnet, $\mathrm{Er}_{3} \mathrm{Al}_{5} \mathrm{O}_{12}$, shown in figure $\mathrm{I}$, $\varepsilon_{\lambda}$ (eq. (18)) was calculated for an emitter with a platinum substrate, a thickness $\mathrm{d}=0.63 \mathrm{~mm}$ and a substrate temperature. $T_{s}=16.35 \mathrm{~K}$. Results for the platinum index of refraction were obtained from reference 17 . The $\varepsilon_{\lambda}$ 
results for $800 \leq \lambda \leq 2000 \mathrm{~nm}$ are shown in figure 3 for $\Delta \mathrm{T}=0$ and $\Delta \mathrm{T}=0.08$. As can be seen, in the emission bands centered at $\lambda \approx 1000 \mathrm{~nm}$ and $\lambda \approx 1500 \mathrm{~nm}$, where the extinction coefficient is large, the spectral emittance is greatly reduced in going from $\Delta \mathrm{T}=0$ to $\Delta \mathrm{T}=0.08$. Outside the emission bands, where the extinction coefficient is much smaller, the spectral emittance is not greatly effected by $\Delta \mathrm{T}$.

Obviously $\Delta \mathrm{T}$ can be reduced by decreasing the thickness, $\mathrm{d}$. However, decreasing $\mathrm{d}$ also reduces the optical depth, $K_{d}=\alpha_{\lambda} d$, which will result in reduced $\varepsilon_{\lambda}$. Thus varying d produces counteracting effects on $\varepsilon_{\lambda}$. Decreasing $d$ will reduce $\Delta \mathrm{T}$, which will increase $\varepsilon_{\lambda}$. But decreasing $\mathrm{d}$ will also reduce $\mathrm{K}_{\mathrm{d}}$, which will decrease $\varepsilon_{\lambda}$. As a result, there will be an optimum thickness, $\mathrm{d}$, to obtain a maximum $\varepsilon_{\lambda}$.

\section{Effect of Doping Level on Extinction Coefficient of $\mathrm{Ho}_{\mathrm{x}} \mathrm{Y}_{3-\mathrm{x}} \mathrm{Al}_{5} \mathrm{O}_{12}$}

The extinction coefficient, $a_{1}$, is the critical optical property for determining spectral emittance, $\varepsilon_{\lambda}$, since the optical depth, $\mathrm{K}_{\mathrm{d}}=\alpha_{\lambda} \mathrm{d}$, is directly proportional to $\alpha_{\lambda}$. Large $\alpha_{\lambda}$ will result in large $\varepsilon_{\lambda}$. Therefore, to evaluate the effect of doping level on the emittance of holmium doped YAG we measured the extinction coefficient for a series of doping levels. The results of these measurements are shown in figure 4 for the wavelength range $1700 \leq$ $\lambda \leq 2200 \mathrm{~nm}$. This shows the main emission band of Ho which results from electronic transitions from the first excited state manifold, ${ }^{5} \mathrm{I}_{7}$, to the ground state manifold, ${ }^{5} \mathrm{I}_{8}$.

As figure 4 shows the extinction coefficient is a monotonically increasing function of the Ho doping level. The maximum extinction coefficients in the emission bands double in going from $\mathrm{Ho}_{1.2} \mathrm{Y}_{1.8} \mathrm{Al}_{5} \mathrm{O}_{12}$ to pure holmium aluminum garnet, $\mathrm{Ho}_{3} \mathrm{Al}_{5} \mathrm{O}_{12}$. However, a doubling of $\alpha_{\lambda}$ in an emission band where $\alpha_{\lambda}$ is already large does not translate into a doubling of $\varepsilon_{\lambda}$. For large $\alpha_{\lambda}$ and thus large $K_{d}$ the emittance is independent of $\alpha_{\lambda}$ (ref. 15). The benefit of a large extinction coefficient is that the thickness, $\mathrm{d}$, can be reduced while still maintaining a large optical depth $K_{d} \geq 1$ ). Thus the smaller $d$ will result in a smaller temperature gradient which in turn will increase $\varepsilon_{\lambda}$.

The same effect of doping level on extinction coefficient has been established for $\mathrm{Er}_{x} \mathrm{Y}_{3-\mathrm{x}} \mathrm{Al}_{5} \mathrm{O}_{12}$ (ref. 15). Due to their similar atomic structure we expect the same increase in $\alpha_{\lambda}$ with increasing doping level for all the rare earths. Panitz (ref. 18) has found similar results for Yb doping of YAG.

\section{Spectral Emittance of Emitting Film of $\mathrm{Er}_{3} \mathrm{Al}_{5} \mathrm{O}_{12}$ and $\mathrm{Ho}_{3} \mathrm{Al}_{5} \mathrm{O}_{12}$}

Figure 5 compares the measured and calculated film spectral emittance of erbium aluminum garnet. $\mathrm{Er}_{3} \mathrm{Al}_{5} \mathrm{O}_{12}$. for a sample of thickness, $d=0.63 \mathrm{~mm}$, with a $P t$ foil substrate. The substrate temperature was $T_{s}=16.35 \mathrm{~K}$ and the measured temperature gradient was $\Delta \mathrm{T}=0.08$. The experimental measurement of $\varepsilon_{\lambda}$ is explained in reference 15 . Figure 5 (a) shows the wavelength region $600 \leq \lambda \leq 10,000 \mathrm{~nm}$ while figure 5 (b) shows an expanded view of the emission band region $800 \leq \lambda \leq 2000 \mathrm{~nm}$. Er has four emission bands associated with electronic transitions from the first 4 excited state manifolds to the ground state. The most intense band centered at $\lambda \approx 1500 \mathrm{~nm}$ results from transitions from the first excited state manifold $\left({ }^{4} \mathrm{I}_{13 / 2} \rightarrow{ }^{4} \mathrm{I}_{15 / 2}\right)$. The other three bands centered at $\lambda \approx 1000 \mathrm{~nm}, 800 \mathrm{~nm}$ and $640 \mathrm{~nm}$ result from transitions of the next three excited state manifolds $\left({ }^{4} \mathrm{I}_{11 / 2} \rightarrow{ }^{4} \mathrm{I}_{15 / 2},{ }^{4} \mathrm{I}_{9 / 2} \rightarrow{ }^{4} \mathrm{I}_{15 / 2}\right.$ and $\left.{ }^{4} \mathrm{~F}_{92} \rightarrow{ }^{4} \mathrm{I}_{15 / 2}\right)$. The large emittance in the region $\lambda \geq 5000 \mathrm{~nm}$ results from the vibrational modes of the crystal lattice. As pointed out in the Introduction, this long wavelength cutoff region occurs for most all high temperature ceramic materials.

There is good agreement between the measured and calculated (eq. (18)) spectral emittance except for the region $1800 \leq \lambda \leq 6000 \mathrm{~nm}$. In the region $1800 \leq \lambda \leq 4000 \mathrm{~nm}$ where the extinction coefficient is small the main contribution to the emittance comes from the $\mathrm{Pt}$ substrate. Error in the measured extinction coefficient is the reason the calculated $\varepsilon_{\lambda}$ is larger than the measured value in the $1800 \leq \lambda \leq 4000 \mathrm{~nm}$ region (ref. 15).

For the region $4000 \leq \lambda \leq 6000 \mathrm{~nm}$ the vibrational modes of the crystal lattice are the primary source of the emission. The extinction coefficient was measured at room temperature. Therefore, the calculated $\varepsilon_{\lambda}$ for $4000 \leq \lambda$ $\leq 6000 \mathrm{~nm}$ corresponds to room temperature conditions. Since the calculated $\varepsilon_{\lambda}$ is less than the experimental $\varepsilon_{\lambda}$ in the $4000 \leq \lambda \leq 6000 \mathrm{~nm}$ region we conclude that the crystal lattice structure is changing with temperature such that higher energy (shorter wavelength) modes exist. These new modes produce the increase in extinction coefficient in the $4000 \leq \lambda \leq 6000 \mathrm{~nm}$ region. In the emission band region, $600 \leq \lambda \leq 1800 \mathrm{~nm}$ electronic transi-tions of the $\mathrm{Er}$ ions account for the radiation. Therefore, widening of the emission bands is the expected effect for increasing temperature rather than increasing extinction coefficient. This conclusion is substantiated since there is good agreement 
hetween experimental and calculated $\varepsilon_{\lambda}$ for $600 \leq \lambda \leq 1800 \mathrm{~nm}$ with the experimental emission bands being somewhat broader. The resolution of the extinction coefficient data was much greater than experimental $\varepsilon_{\lambda}$ data. As a result, the calculated $\varepsilon_{\lambda}$ shows more structure in the emission bands.

As a measure of the effectiveness of $\mathrm{Er}_{3} \mathrm{Al}_{5} \mathrm{O}_{12}$ as a selective emitter we define the emitter efficiency as follows.

$$
\eta_{E} \equiv \frac{\text { useful radiated power }}{\text { total radiated power }}=\frac{\int_{0}^{\lambda} q_{\lambda}(\mathrm{d}) \mathrm{d} \lambda}{\int_{0}^{\infty} q_{\lambda}(\mathrm{d}) \mathrm{d} \lambda}=\frac{\int_{0}^{\lambda,} \varepsilon_{\lambda} \mathrm{e}_{\mathrm{bs}}\left(\lambda, \mathrm{T}_{\mathrm{s}}\right) \mathrm{d} \lambda}{\int_{0}^{\infty} \varepsilon_{\lambda} \mathrm{e}_{\mathrm{bs}}\left(\lambda, \mathrm{T}_{\mathrm{s}}\right) \mathrm{d} \lambda}
$$

The numerator is the power radiated in the wavelength region $0 \leq \lambda \leq \lambda_{f}$, where $\lambda_{f}$ is the wave-length at the end of the main emission band $\left(\lambda_{\ell}=1650 \mathrm{~nm}\right.$ for $\left.\mathrm{Er}_{3} \mathrm{Al}_{5} \mathrm{O}_{12}\right)$. The denominator is the total radiated power. As shown in figure 5 the calculated efficiency is $\left.\eta_{\mathrm{E}}\right|_{\text {cal }}=0.20$ and the experimental efficiency is $\left.\eta_{\mathrm{E}}\right|_{\exp }=0.21$. The theoretical efficiency is smaller because $\left.\varepsilon_{\lambda}\right|_{c a l}$ is too large in the $1800 \leq \lambda \leq 4000 \mathrm{~nm}$ region. The blackbody emissive power, $e_{b s}\left(\lambda, T_{s}\right)$, is a sensitive function of $T_{s}$. As a result $\eta_{E}$ is also a sensitive function of $T_{s}$. For $d=0.3 \mathrm{~mm}$, $\mathrm{T}_{\mathrm{s}}=1234^{\circ} \mathrm{K}$ and $\Delta \mathrm{T}=0.094$ the measured efficiency is reduced to $\left.\eta_{\mathrm{E}}\right|_{\text {exp }}=0.065$.

Figure 6 compares calculated and measured values of $\varepsilon_{\lambda}$ for $\mathrm{Ho}_{3} \mathrm{Al}_{5} \mathrm{O}_{12}$ on a Pt substrate with $\mathrm{d}=0.3 \mathrm{~mm}$. The substrate temperature was $\mathrm{T}_{\mathrm{s}}=1446 \mathrm{~K}$ and $\Delta \mathrm{T}=0.0692$. Similar to $\mathrm{Er}_{3} \mathrm{Al}_{5} \mathrm{O}_{12}, \mathrm{Ho}_{3} \mathrm{Al}_{5} \mathrm{O}_{12}$ has emission bands that originate from transitions to the ground state from the 4 lowest excited states; ${ }^{5} \mathrm{I}_{7} \rightarrow{ }^{5} \mathrm{I}_{8}$ centered at $\lambda \approx 2000 \mathrm{~nm}$, ${ }^{15} \mathrm{I}_{6} \rightarrow{ }^{5} \mathrm{I}_{8}$ centered at $\lambda \approx 1200 \mathrm{~nm},{ }^{5} \mathrm{I}_{5} \rightarrow{ }^{5} \mathrm{I}_{8}$ centered at $\lambda \approx 900 \mathrm{~nm}$ and ${ }^{5} \mathrm{I}_{4} \rightarrow{ }^{5} \mathrm{I}_{8}$ centered at $\lambda \approx 650 \mathrm{~nm}$. The first excited state to ground state transition $\left({ }^{5} \mathrm{I}_{7} \rightarrow{ }^{5} \mathrm{I}_{8}\right.$ ) has the largest intensity. Also similar to $\mathrm{Er}_{3} \mathrm{Al}_{5} \mathrm{O}_{12}$, but not shown in figure 6 , the long wavelength region of large emittance begins at $\lambda \approx 5000 \mathrm{~nm}$. Similar to $\mathrm{Er}_{3} \mathrm{Al}_{5} \mathrm{O}_{12}$, there is good agreement between the experimental and theoretical emittance in the emission band regions. Also, because of experimental error in the extinction coefficient for the region $\lambda>2200 \mathrm{~nm}$ the theoretical emittance is too large. For $\mathrm{Ho}_{3} \mathrm{Al}_{5} \mathrm{O}_{12}$ the measured emitter efficiency using $\lambda_{\ell}=2150 \mathrm{~nm}$ in $\mathrm{Eq}$. (35) is $\eta_{\mathrm{E}} \mathrm{l}_{\text {exp }}=0.34$. The larger $\eta_{\mathrm{E}}$ for $\mathrm{Ho}_{3} \mathrm{Al}_{5} \mathrm{O}_{12}$ compared to $\eta_{\mathrm{E}}$ for $\mathrm{Er}_{3} \mathrm{Al}_{5} \mathrm{O}_{12}$ results because the integration limit, $\lambda_{f}$, in equation (35) is larger for $\mathrm{Ho}$ $\left(\lambda_{f}=2150 \mathrm{~nm}\right)$ than $\operatorname{Er}\left(\lambda_{\ell}=1650 \mathrm{~nm}\right)$. At $\mathrm{T}_{\mathrm{s}}=1270 \mathrm{~K}$ and $\Delta \mathrm{T}=0.062$ the measured efficiency is $\left.\eta_{\mathrm{E}}\right|_{\mathrm{exp}}=0.27$ for the sample in figure 6 .

\section{Spectral Emittance of Emitting Cylinder of $\mathrm{Ho}_{3} \mathrm{Al}_{5} \mathrm{O}_{12}$}

Using equation (31) the spectral emittance of a cylinder of radius, $\mathrm{R}=1.0 \mathrm{~mm}$, of $\mathrm{Ho}_{3} \mathrm{Al}_{5} \mathrm{O}_{12}$ was calculated. These results are shown in figure 7. Comparing the film results for $\mathrm{Ho}_{3} \mathrm{Al}_{5} \mathrm{O}_{12}$ (fig. 6) to figure 7 we see that $\varepsilon_{\lambda}$ is significantly larger in the emission bands for the cylindrical geometry. This results because the cylinder is at uniform temperature whereas the film has a linear temperature gradient.

Obviously a cylinder is more desirable than a film for obtaining large emittance in an emission band. Fibrous emitters of rare earth oxides (refs. 3 and 4 ) are used for combustion driven TPV systems (ref. 19). As mentioned in the Introduction, the fibrous emitters are well suited for coupling energy from a flame. However, for other TPV systems where the source of thermal energy is solar or nuclear the film type emitter is more applicable.

\section{CONCLUSION}

Rare earth ions in high temperature host materials emit in several narrow bands in the near infrared and the visible spectrum. A spectral emittance model for film and cylindrical emitters, where optical depth is the key variable, has been developed. There are many possible host materials although this study includes only rare earth aluminum garnets of Er and Ho. Experimental measurements of the extinction coefficients and spectral emittances of these garnets have been made. The experimental and theoretical spectral emittance results for the film emitter are in good agreement. Maximum spectral emittances of 0.6 to 0.8 occur in the emission bands. At $\lambda>5000 \mathrm{~nm}$ all these 
materials have large emittance $\left(\varepsilon_{\lambda}>0.8\right)$ as a result of emission from the vibrational modes of the crystal structures. Small temperature gradients $(\Delta \mathrm{T}<0.1)$ across the film emitters result in significant reductions in spectral emittance. Because spectral emittance increases with optical depth but decreases with temperature gradient there is an optimum film thickness for maximum emittance. For operating conditions of interest, the film emitter has a linear temperature variation whereas the cylindrical emitter has a uniform temperature. Thus, the cylinder has larger spectral emittance in the emission bands. Emitter efficiency is a sensitive function of temperature. For holmium aluminum garnet $\left(\mathrm{Ho}_{3} \mathrm{Al}_{5} \mathrm{O}_{12}\right)$ the efficiency at $\mathrm{T}_{\mathrm{S}}=1446 \mathrm{~K}$ for film thickness, $\mathrm{d}=0.3 \mathrm{~mm}$, and temperature gradient, $\Delta \mathrm{T}=0.069$ is $\left.\eta_{\mathrm{E}}\right|_{\text {exp }}=0.34$ and at $\mathrm{T}_{\mathrm{s}}=1270 \mathrm{~K}$ with $\Delta \mathrm{T}=0.062$ the efficiency is $\left.\eta_{\mathrm{E}}\right|_{\text {exp }}=0.27$.

\section{REFERENCES}

1. Dieke, G.H., Spectra and Energy Levels of Rare Earth Ions in Crystals, Interscience, New York, 1968.

2. Guazzoni, G.E., High-temperature spectral emittance of oxides of erbium, samarium, neodymium and ytterbium. Appl. Spectrose. 1972; 26: 60-65.

3. Nelson, R.E., Rare earth oxide TPV emitters. in Proc. 32nd International Power Sources Symposium (Electrochemical Society, Pennington, NJ) 1986, pp. 95-101.

4. Parent, C.R. and Nelson, R.E., Thermophotovoltaic energy conversion with a novel rare earth oxide emitter, in Proc. 21 st IECEC. (Am. Chem. Soc., Washington, DC) 1986, pp. 1314-1317.

5. Chubb, D.L., Reappraisal of solid selective emitters in Proc. 21st IEEE PV Specialist Conf. 1990, pp. 1326-1333. Also NASA TM-103290.

6. Chubb, D.L. and Lowe, R.A. Thin Film Selective Emitter. J. Appl. Phys. 1993; 74(9) pp. 5687-5698.

7. Lowe, R.A., Chubb, D.L., Farmer, S.C., and Good, B.S., Rare-earth garnet selective emitter. Appl. Phys. Lett. 1994; 64 (26) pp. 3551-3553.

8. Lowe, R.A.. Chubb, D.L., and Good, B.S., Radiative performance of rare earth garnet thin film selective emitters. in Proc. of the First NREL Conf. on Thermophotovoltaic Generation of Electricity: 1994. AIP Conf. Proc. 321, pp. 291-297.

9. Lowe, R.A., Chubb, D.L., and Good, B.S, The effect of temperature on the radiative performance of Ho-YAG thin film selective emitters. in Proc. of the First World Conf. on Photovoltaic Energy Conversion; 1995 IEEE. vol. II, pp. 1851-1854.

10. Lowe, R.A., Good, B.S., and Chubb, D.L., The effect of thickness and temperature on the performance of thin film selective emitters for thermophotovoltaic applications. in Proc. of 30th IECEC; 1995 American Society of Mechanical Engineers, vol. 2. pp. 511-515.

11. Chubb, D.L., Lowe, R.A., and Good, B.S., Emittance theory for thin film selective emitter, in Proc. of First NREL Conf. on Thermophotovaltic Generation of Electricity, 1994, AIP Proc. 321, pp. 229-244.

12. Good, B.S., Chubb, D.L., and Lowe, R.A., Temperature-dependent efficiency calculations for a thin-film selective emitter. in Proc. of First NREL Conf. on Thermophotovaltic Generation of Electricity, 1994, AIP Proc. 321, pp. 263-275.

13. Chubb, D.L., Good, B.S., Clark, E.B., and Chen, Z. Effect of temperature gradient on thick film selective emitter emittance, presented at The Third NREL Conference on Thermophotovoltaic Generation of Electricity, AIP Conference Proceedings 401, 1997

14. Siegel, R. and Howell, J.R., Thermal radiation heat transfer, 2nd edition, Washington, DC. Hemisphere, 1981, Chs. $4,14$.

15. Chubb, D.L., Pal, A.T., Patton, M.O., and Jenkins, P.P. Rare earth doped high temperature ceramic selective emitters, NASA TM-208491, also to appear in Journal of the European Ceramic Society.

16. Chubb, D.L. Emittance theory for cylindrical fiber selective emitter," The Fourth NREL Conf. on Thermo photovoltaic Generation of Electricity, AIP Conf. Proc. 460, pp. 463-471, also NASA TM-1998-208656.

17. Lide, D.R., (Ed.), CRC Handbook of Chemistry and Physics, 71 st ed., CRC Press, 1990.

18. Panitz, J.-C., Schubnell, M., Durisch, W., and Geiger, F., Influence of ytterbium concentration on the emissive properties of $\mathrm{Yb}: \mathrm{YAG}$ and $\mathrm{Yb}: \mathrm{Y}_{2} \mathrm{O}_{3}$, in Proceedings of The Third NREL Conference on Thermophotovoltaic Generation of Electricity, ÄP Conf. Proc. 4011997. 


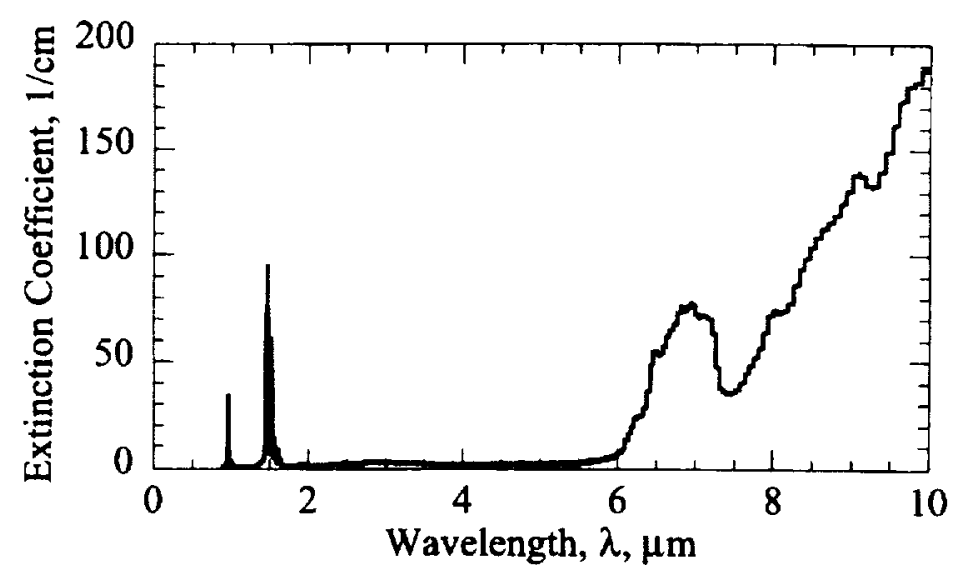

Fig. 1. Extinction coefficient for erbium aluminum garnet $\left(\mathrm{Er}_{3} \mathrm{Al}_{5} \mathrm{O}_{12}\right)$. 


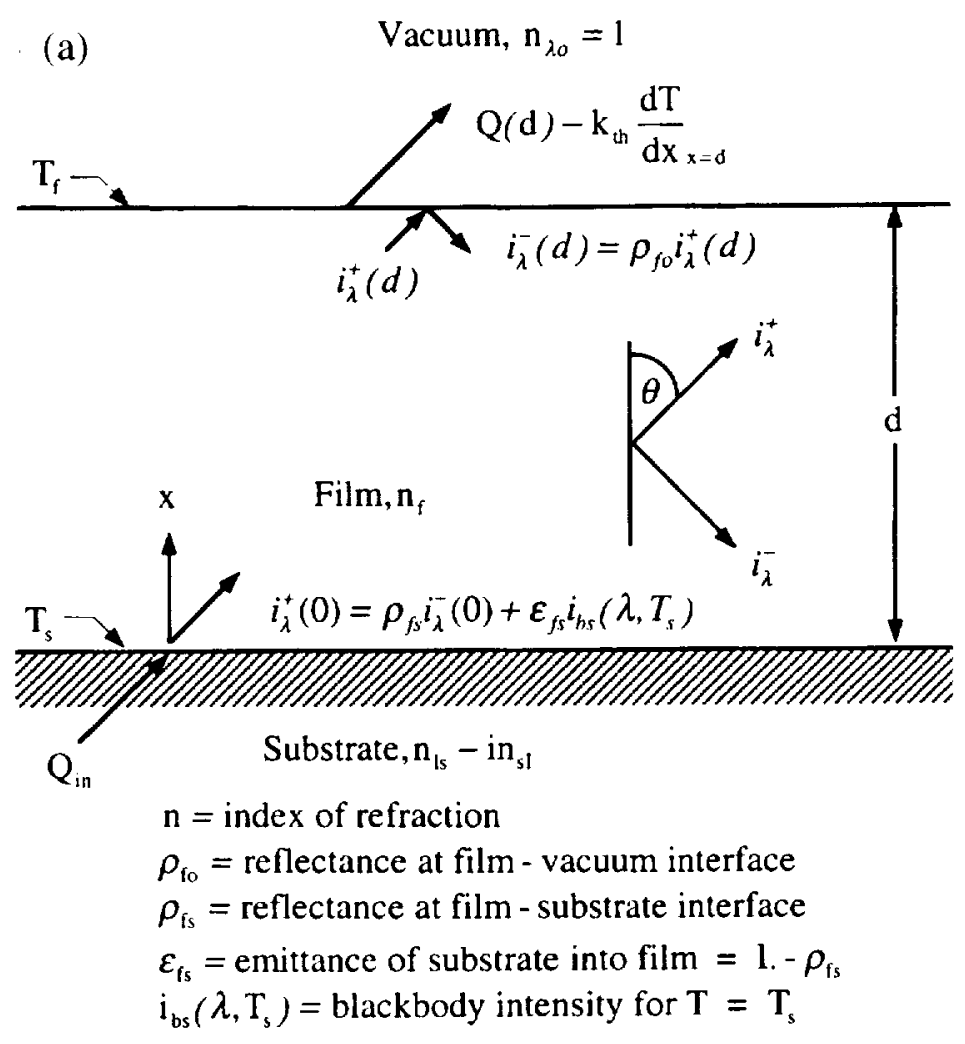

(b)

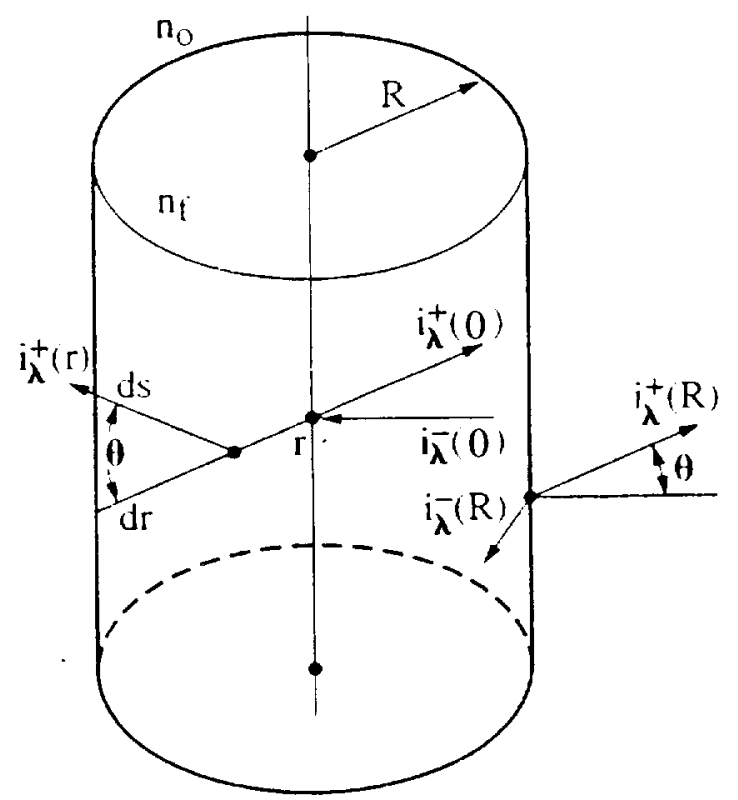

$$
\begin{aligned}
& n_{\varphi}=\text { index of refraction of cylinder } \\
& n_{0}=\text { index of refraction of surroundings } \\
& \cos \theta \text { ds }=d r
\end{aligned}
$$

Fig. 2. Schematics of emitting film and cylinder. (a) Emitting film. (b) Emitting cyclinder. 


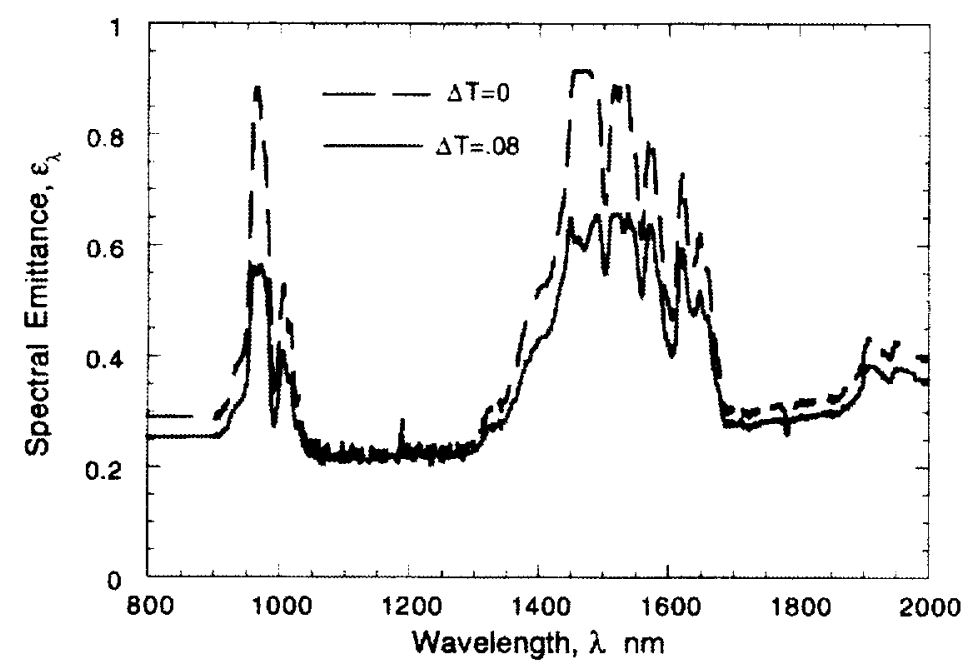

Fig. 3. Effect of temperature gradient on spectral emittance of $\mathrm{Er}_{3} \mathrm{Al}_{5} \mathrm{O}_{12}$ with platinum substrate for $T_{S}=1635 \mathrm{~K}$ and $d=0.63 \mathrm{~mm}$.

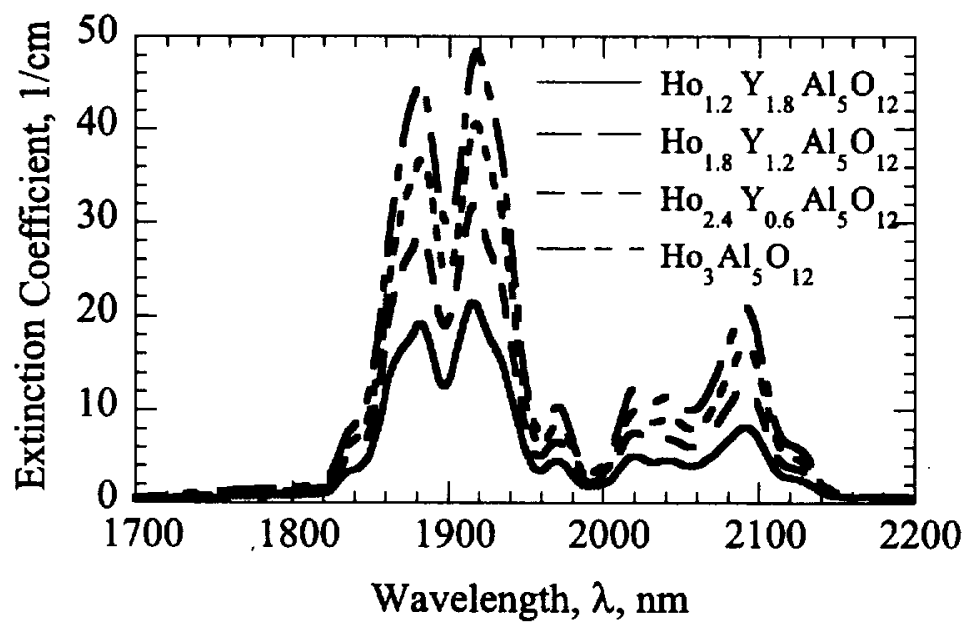

Fig. 4. Effect on extinction coefficient of Ho-doping level in YAG. 

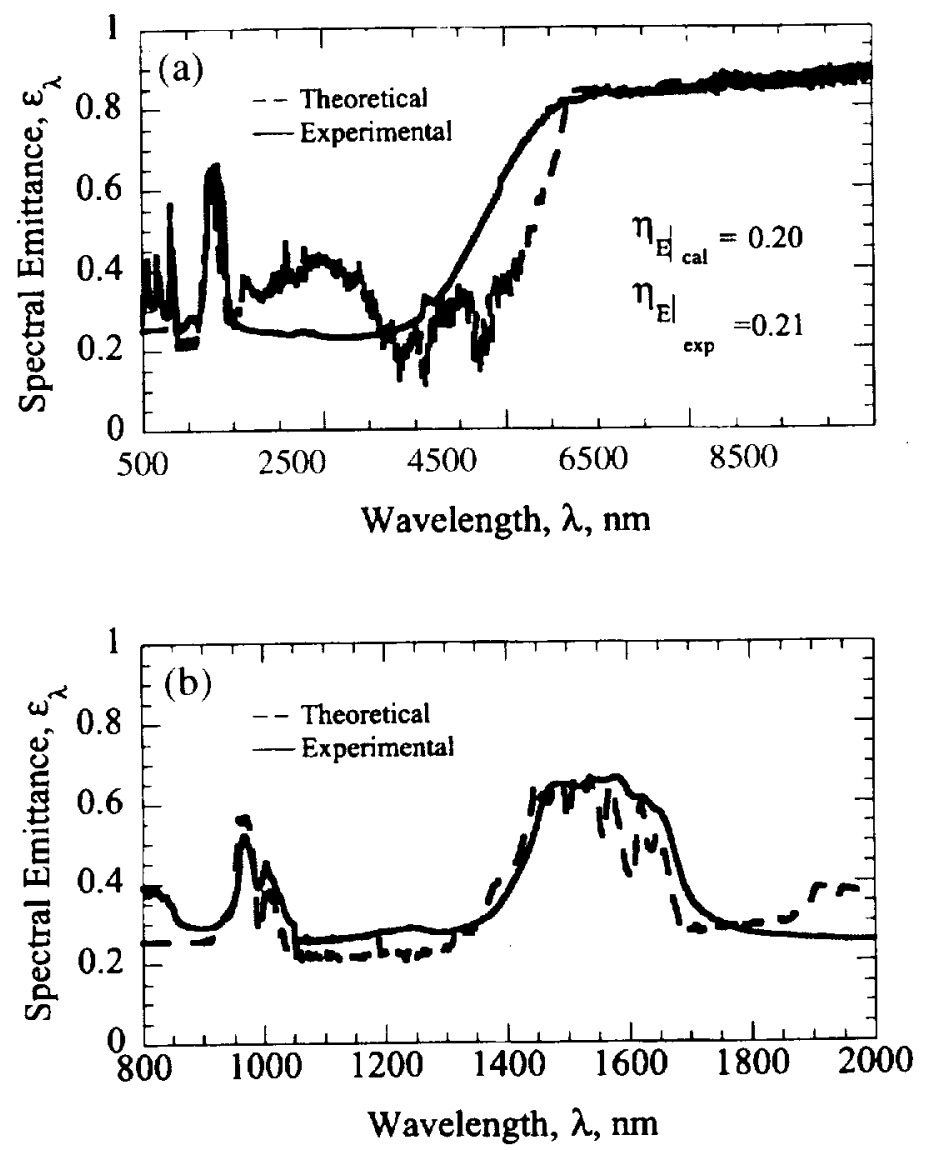

Fig. 5. Comparison of experimental and calculated spectral emittance of Erbium aluminum garnet $\left(\mathrm{Er}_{3} \mathrm{Al}_{5} \mathrm{O}_{12}\right.$ ) with platinum substrate. Thickness, $\mathrm{d}=0.63 \mathrm{~mm}$, substrate temperature, $\mathrm{T}_{\mathrm{S}}=1635 \mathrm{~K}$, front face temperature, $\mathrm{T}_{\mathrm{f}}=1503 \mathrm{~K}, \Delta \mathrm{T}=0.0807$. (a) $600<\lambda<10,000 \mathrm{~nm}$. (b) $800<\lambda<2000 \mathrm{~nm}$. 


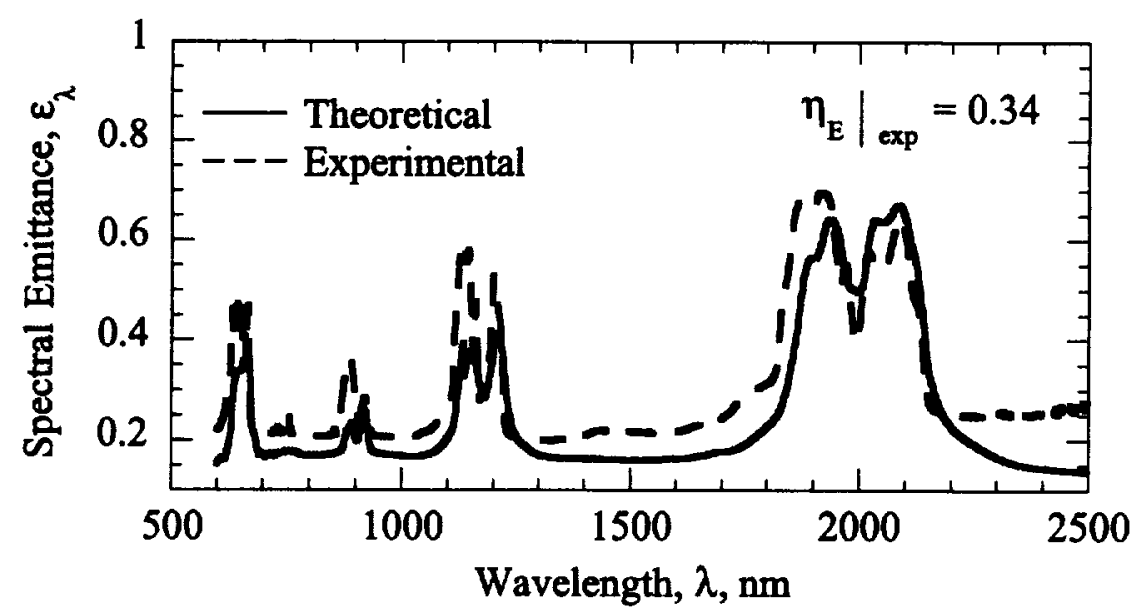

Fig. 6 Comparison of experimental and calculated spectral emittance of Holmium aluminum garnet $\left(\mathrm{Ho}_{3} \mathrm{Al}_{5} \mathrm{O}_{12}\right)$ with platinum substrate. Thickness, $\mathrm{d}=0.3 \mathrm{~mm}$, substrate temperature, $\mathrm{T}_{\mathrm{S}}=1446 \mathrm{~K}$, front face temperature, $T_{f}=1346 \mathrm{~K}, \Delta T=0.0692$.

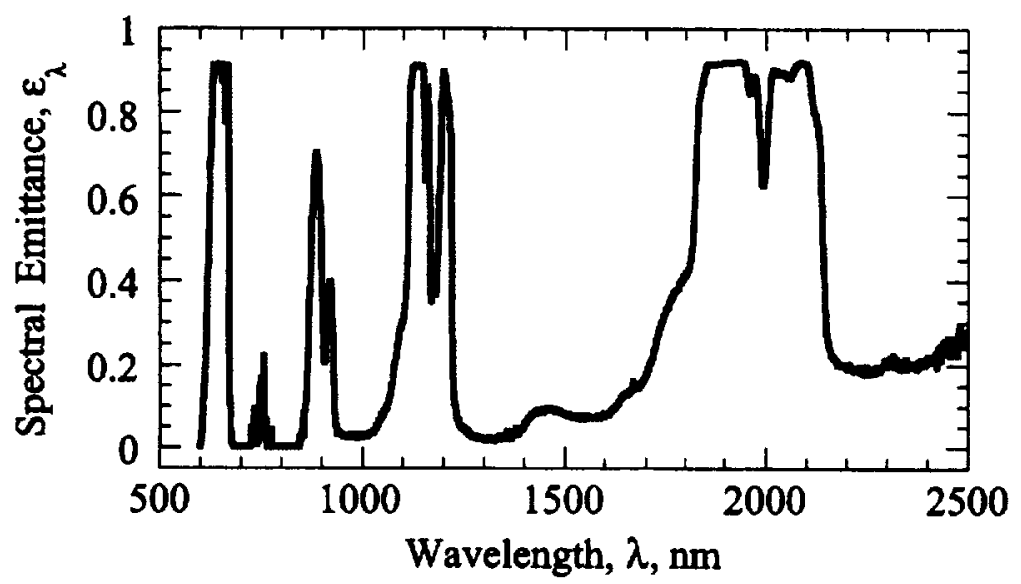

Fig. 7. Caculated emittance for a cylinder of Holmium aluminum garnet $\left(\mathrm{Ho}_{3} \mathrm{Al}_{5} \mathrm{O}_{12}\right)$ with a radius, $r=0.1 \mathrm{~cm}$. 


\begin{tabular}{|c|c|c|c|}
\hline 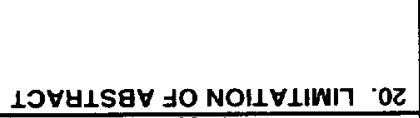 & 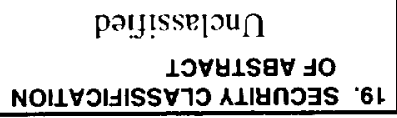 & 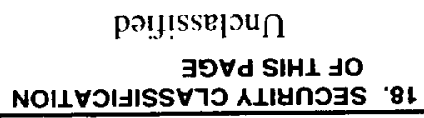 & 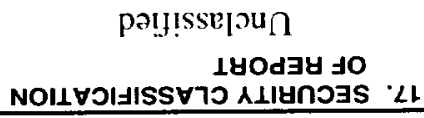 \\
\hline $\mathcal{E O V}$ & & \multirow{3}{*}{ 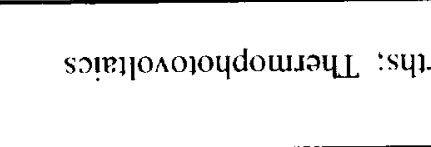 } & \\
\hline 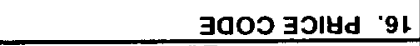 & & & 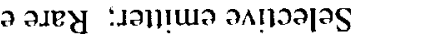 \\
\hline 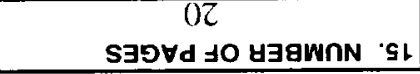 & & & Swy \\
\hline
\end{tabular}

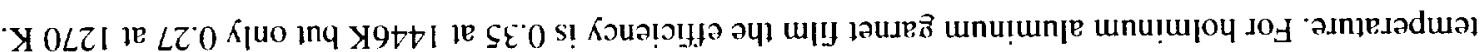
jo uo!̣ounj aᄉ!!!

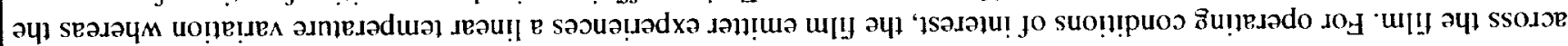

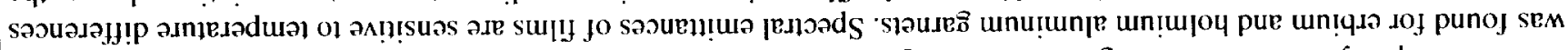

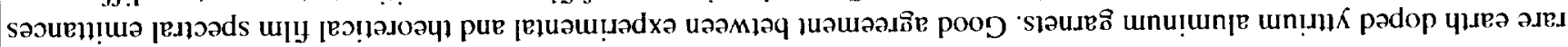

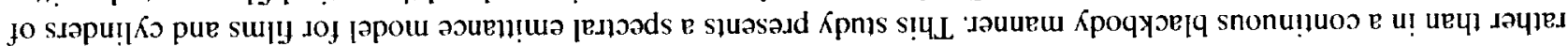

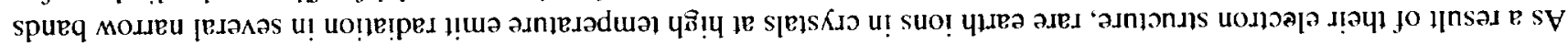

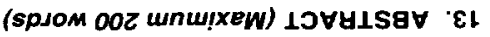

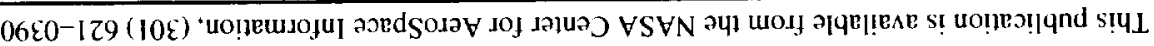

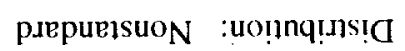

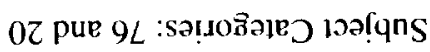
pəl!u!ju - pay!sse[oun

$\tau+\tau \tau-\varepsilon \varepsilon t(9 I \tau)$

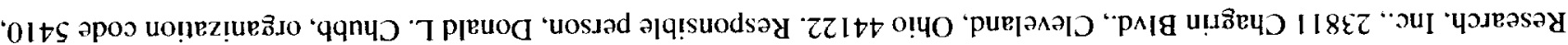

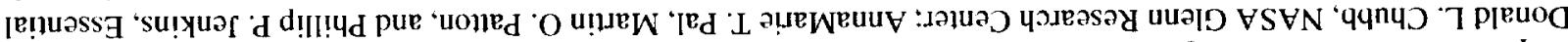

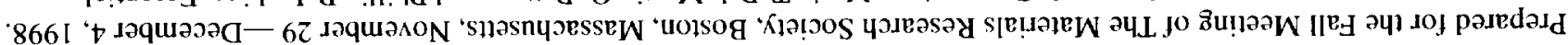

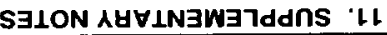

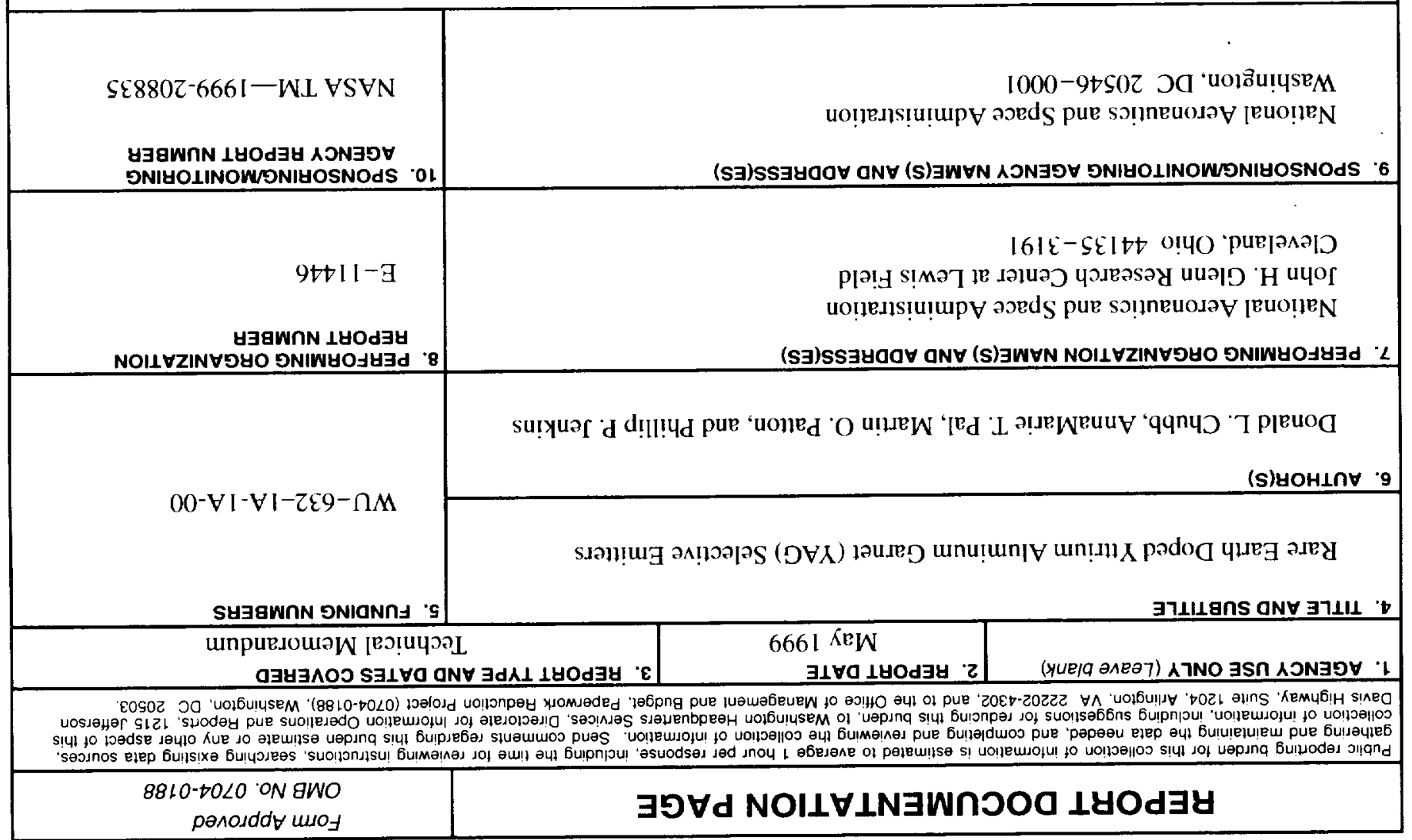


